\title{
Representaciones de Santiago en Huellas de Siglo de Carmen Berenguer: La ciudad burdel
}

\author{
Dra. Magda Sepúlveda*
}

\section{Resumen:}

La ciudad inserta en los flujos del capitalismo fue comparada por Baudelaire, y su lector Benjamin, con la prostituta. En otro contexto, neoliberal y dictatorial, la poeta chilena Carmen Berenguer actualiza el tópico en Huellas de siglo (1986). Berenguer plantea que toda la ciudad se ha transformado en un burdel donde nada se sustrae a convertirse en mercancía, por tanto, la diferencia política y de clase se obliteran. La poeta muestra que, para llegar a esta nueva ciudadanía ideal de carácter prostibular, fue necesario un golpe o 'proceso de ablandamiento' que finaliza con el sujeto consumidor.

Palabras clave: Poesía chilena, dictadura, ciudad

\section{Abstract:}

The city, inserted in the flows of capitalism, was compared by Baudelaire and his reader Benjamin with the prostitute. In another context, neoliberal and dictatorial, the Chilean poet Carmen Berenguer brings up to date the topic in Huellas de Siglo (1986). Berenguer claims that the whole city has become a brothel where everything is a good, and so political and class differences give up. The poet shows that when achieving the mercantile character of the ideal citizenship paradigm, a softening process of the individual was necessary, which results in a consumer.

Key Words: Chilean poetry, dictatorship, city

* Profesora de Literatura Pontificia Universidad Católica de Chile. msepulvu@uc.cl Esta investigación es producto del proyecto Fondecyt N.10.50.321, “¿Neovanguardia, modernidad en disolución, posmodernidad? La poesía chilena entre 1973 y 1988", dirigido por el doctor Naín Nómez y del cual quien suscribe es coinvestigadora. 


\section{Introducción}

Recuerdo la primera vez que vi el video de Diamela Eltit leyendo en un burdel y luego lavando la acera contigua (1980)'․ Yo había pasado sólo por afuera de un sector prostibulario y caminando rápido, evitando la mirada; mientras la escritora se atrevía a entrar y afirmaba su permanencia en el sitio. Cuando años más tarde volví a ver la figura del burdel en un poemario de Carmen Berenguer ${ }^{2}$, pensé que no era casual que dos textos producidos durante la dictadura tomaran tal espacio como motivo en sus representaciones. Intentaré explicar el interés por el burdel en Huellas de siglo de Carmen Berenguer y las inquietudes que me origina el uso de ese referente.

1 Eltit leyó fragmentos de la novela Lumpérica en un prostíbulo santiaguino de la calle Maipú. Sobre dicha acción, ella comenta: "Era una acción de arte en la ciudad. (Era una) relación de Arte, Cuerpo y Ciudad" (Neustadt 99)

2 El periodo de la dictadura militar coincidió, en Chile, con la irrupción en el campo literario de un grupo de mujeres poetas, como no se había dado hasta entonces en la historia literaria nacional. Kemy Oyarzún efectúa un análisis de la producción poética de mujeres del período, identificando ciertas constantes, como: enfrentamiento con la ley del Padre, discusión de los emblemas nacionales, referencia de sí mismas como expatriadas, las mujeres estarían en un inxilio, hablantes que se autocuestionan y autodevaluán, "en un plano linguístico, las figuras del silencio proliferan, (un) silencio que refiere a condiciones productivas" (17) y denuncia del poder en su cualidad corporal y sexual Entre este grupo destaca Carmen Berenguer (1946) con sus libros de poesía: Bobby Sands desfallece en el muro (1983), Huellas de siglo (1986), A media asta (1988), Sayal de pieles (1993), Naciste pintada (1999), La gran hablada (2002) y Mama Marx (2007). Berenguer ha sido incluida en numerosas antologías y ha recibido variadas distinciones, entre ellas la beca Guggenheim (1997). Su obra he recibido los análisis de importantes críticas, entre ellas, Kemy Oyarzún, Eugenia Brito, Raquel Olea y Francine Masiello. De este grupo, comento más extensamente a Raquel Olea y Eugenia Brito, pues ella se ha detenido en Huellas de siglo, libro que me parece fundamental en su vinculación mujer y ciudad. 


\section{La ciudad burdel, lugar de identidades}

De Huellas de siglo, Raquel Olea ha indicado la importancia del tema de la ciudad "en esta emergente poesía de la década del '80 donde por primera vez aparece una sujeto que habla la urbe desde un lugar femenino" (133) y que, en este libro en particular se traduce en "la corporeización de los espacios urbanos" (133) donde se constituye un "sujeto escritural transeúnte y nómade, caminante de lugares (in) habitables de lo urbano abandonado, desposeído, arruinado por el curso y la estratifucación del progreso y la modernización" (133). Por su parte, Eugenia Brito ha indicado que la ciudad es apreciada como "espectáculo, desenmascarando aquello que la acusa como cuerpo tomado, (lo que explica) la cita de Gonzalo Millán que sirve como epígrafe: "los maniquiés lucen saludables. Son felices" (y hace comprensible la demarcación de una territorialidad) alienada en el consumismo" (167). La crítica ha distinguido la relación ciudad- mujer y el cruce ciudad-mercado, tablero al cual me interesa agregar la noción de burdel e intentar explicar los vínculos ciudad, mujer, mercado, y prostíbulo ${ }^{3}$ más las inquetudes que estas aociaciones me provocan.

Berenguer propone una analogía entre la prostituta y la ciudad. Escuchemos el poema "Santiago Tango" que funciona como un pivote a través del cual gira todo el libro:

Carente de decencia, marginal, fantoche

Patipelá, espingarda ciudad.

Se nos muere esta loca

Con una estocada en el lado izquierdo

De su rostro oculto.

Pobre dama, empielada ramera

Transpirando polen

La noche escuálida te dobla

Donde duerme el cafiche (17)

3 La figura del prostíbulo en la narrativa latinoamerica del siglo XX ha sido estudiada por Rodrigo Cánovas, quien ve el uso del burdel como un "espacio para reflexionar sobre la marginalidad y en especial, sobre los órdenes culturales, (mediante) la pregunta por la moderrnidad, que es descompuesta desde la pregunta por las reglas sexuales" (5). En el colofón chileno, Cánovas elabora tres modelos del burdel nacional. Primero, la prostitución como caída que se genera a partir del comercio sexual obligado entre el patrón y la mujer de clase media, un vínculo interclase fuera de lo público que la lleva al lugar vicioso. Segundo, el prostíbulo es visto como lugar decadente "generado por la oligarquía criolla" (176). Tercero, el burdel como espacio de representación de la familia chilena con sus roles masculino y femeninos alterados. Desde ya, anticipo que el prostíbulo en la ficción poética de Berenguer establece cambios y continuidades con estos modelos que se entienden, por la inscripción en un contexto dictatorial. 
La prostituta y la ciudad compartirían un estado "carente de decencia", "marginal", "pobre dama", "empielada" y "sometida a un cafiche". La simbiosis entre ciudad moderna y prostituta fue analizada por Benjamín en sus interpretaciones sobre Baudelaire.El crítico alemán situó a la prostituta en el regimen de la mirada, dada su necesidad de ser vista, tal como la ciudad moderna que, con sus pasajes y vitrinas, se hizo apta para el paseo y la mirada hacia las mercancías. En la simbiosis entre prostituta y ciudad, Benjamín destaca el doblez de "la prostituta que es a la vez vendedora y mercancía" (185). Además, la prostituta se reviste de una apariencia seductora que oculta su marginalidad, de la misma forma que la ciudad moderna esconde su premodernidad. El tópico es entonces antiguo, ¿qué le agrega Berenguer? Berenguer actualiza el tópico al situarlo en un contexto neoliberal, ahí radican sus aportes, no obstante su representación posee un signo ambiguo, ya que no logra escapar de la asociación mujer, espacio público y ramera ${ }^{4}$.

La denominación de la urbe como "ramera" (Berenguer 17) apela a la polis movida por el paradigma económico neoliberal, cuya ideología " tuvo su primera oportunidad histórica en América Latina justamente en Chile, cuando en 1975, Pinochet entregó el Ministerio de la Economía a Sergio Castro y sus "Chicago Boys" (Comblin 10). Esta política consistía en abandonar la estrategia de la industrialización y sustituirla por la entrada de importaciones. Berenguer recrea el efecto recrea de esta política al poetizar la figura del mercado como mediador de equivalencia entre significantes heterogéneos. La poeta destaca la anulación de la diferencia que va produciendo el nuevo modelo económico, por ejemplo, los diversos estilos vestimentarios de los habitantes que son signos supuestamente de ideologías diferentes, son presentados por la poeta como homologados por la moda: "jeans, sweaters de cachemira / (beau) monde. Jet-set rightists / jet-set leftits/pantaloncitos bomba/pañuelito hindú" (11). El liberalismo hizo equivalente el chaleco de cachemira con el pañuelito hindú, obliteró el lugar de procedencia y lo reemplazó por el sitio de la fábrica trasnacional: en la nueva industria de la moda, el pañuelito hindú no proviene de Nueva Delhi y el sweater no es de Cachemira ${ }^{5}$. Bajo el estilo 'estar a la moda', Berenguer iguala la izquierda de pañuelito hindú y la derecha de sweaters de cachemira, esto es, se caen los viejos proyectos ilustrados, y se establece la convivencia de

$4 \quad$ "Desde un punto de vista falocéntrico, las mujeres vienen a representar (el) caos y la oscuridad, igualando todas a la prostituta de Babilonia, y; adorarlas en otras ocasiones por creerlas la encarnación de la más pura naturaleza, venerándolas como a vírgenes y madres de Dios" (Moi 174).

5 Luis Ernesto Cárcamo ha estudiado este tema en las crónicas De perlas y cicatrices del escritor chileno Pedro Lemebel, concluyendo una situación que es coincidente con lo sostenido por Berenguer, en términos que estos textos delatan que la ciudadanía se legitima en la idea misma de mercado y que Chile," producto de la transformación dictatorial, es una sociedad plenamente penetrada por la motivación mercantil". (p...) 
todo aquel que respete la moda, vale decir, la ciudadanía se afirma en el consumir, la hablante ya no puede seleccionar, pues todo se rige por la entidad totemizada del mercado. La voz enumera y critica la multiplicidad aparente que se mueve bajo el consumo, proponiendo que la ciudadanía ideal, la prostituta, podrá asumir cualquier ideología, pues toda idea es para ella una moda.

La ciudad, entendida como burdel, se constituye en el lugar donde incluso las identidades son intercambiables. Por ejemplo, las ofertas identitarias de la metrópoli comparten el estilo de llevar el pelo corto: "rapaditos Hare Krishna Hare Hare / sudoroso mormón en bicicleta/(...)/ Footing, footing a los cerros" (Berenguer 12). El ciudadano hare krisna, el mormón y el yuppie comparten la moda militar. Berenguer sólo rescata al punk que ha transformado su modo de llevar el pelo en un gesto semiótico visual de rebeldía y usa ropajes militares asumiendo el estado de guerra como escenario vital y permanente; los demás usan el uniforme sin saberlo. De la misma forma, la pluralidad étnica es eliminada bajo el rótulo del mercado: "Parque Arauco/ Lonconao / Rapa-nui en botellas" (12). La presencia étnica, como cualquier diferencia, sucumbe ante la neutralización del mercado, presentándose como un producto más para adquirir. El mercado ofrece tranquilidad, no hay religión peligrosa o etnia subversiva, en la medida que participan desde el interior o mirando la vitrina. Por ello, una vez instalado el neoliberalismo no será necesaria la dictadura. Según Berenguer, la ciudad neoliberal, tal como el burdel, no repara en la ideología política, la religión o la etnia de los clientes.

Berenguer define el Santiago neoliberal como "carente de decencia", lo que equivale a indicar que le "falta de aseo, compostura y adorno" (RAE.). La limpieza fue un núcleo del discurso dictatorial ${ }^{6}$ que pretendía hacer coincidir la acepcia del mercado económico, con el aseo de la casa y la higiene política. Por tanto no es extraño que se torture al mismo tiempo que se liberalice el mercado. El poemario repara en esta coincidencia y liga la violencia a un saber doméstico. Las prácticas de limpieza política se ejercieron en 'casas de la dictadura', que es curiosamente el nombre que recibían los domicilios secretos donde se torturaba. La hablante reelabora la frase cliché 'casas de la dictadura' para destacar la palabra 'casa' y las prácticas de 'limpieza' que en ella se efectuaban:

Me golpearon ("para ablandarme")

Me lavaron ("para limpiarme")

Ejemplo de este discurso de limpieza se obserba en el saludo que Pinochet da a la ciudadanía desde el Palacio de la Moneda el 11 de marzo de 1981 decía: "Señores, deseamos unidad limpia y pura, no alianzas ni componendas que sólo entraban lo expédito de nuestro camino" (107). 
Entonces, golpeado, ultrajado, semiblando

y limpio

me colocaron en una olla con agua hirviendo

y sal.

Ahora estoy en la cocina

con mayonesa, cebolla y perejil.

Ahora estoy en la vitrina.

Ahora estoy en un cartel (21).

Aquí Berenguer se define retóricamente por "el uso de ciertos recursos linguísticos que pertenecientes a hablas coloquiales chilenas efectuán trasposiciones de los significados dichos" (Olea 134) ${ }^{7}$. En el poema los procedimientos de tortura son saberes del mundo privado en tanto, así como en la cocina se machaca, asea y transforma objetos en alimentos, de la misma forma el torturador golpea, limpia y transforma cuerpos en ciudadanos. El acto de 'ablandar' consistía en 'quebrar', vale decir, lograr que un preso delatara a sus compañeros. Berenguer crítica las 'casas de la dictadura', pero también a toda casa. Si las casas se han entendido como un espacio privado ${ }^{8}$ donde es posible suspender el orden jurídico, un islote al que los demás no tenemos derecho a entrar, ¿por qué entonces la dictadura no podía tener sus casas privadas?. La respuesta de Berenguer apunta a eliminar los estados de excepción de cualquier casa, pues ellos permiten, con violencia, el paso de lo crudo a lo cocido. En la 'casa de tortura', se transforma un ciudadano ideológico en un ciudadano- consumidor, de ahí el verso "estar en la vitrina" (21). Los procedimientos de la casa ${ }^{9}$ producen beneficios públicos, hay una consonancia entre "alguien quiere limpiar la casa / alguien quiere limpiar la patria" (Hernández $\mathrm{s} / \mathrm{n}^{10}$ ). En la ciudad burdel se admite que los y las habitantes pueden ser golpeados en cualquier momento.

La otra metáfora femenina sobre la ciudad, es"empielada" (Berenguer 17), con la cual se alude a un ejercicio del género, el del simulacro: la

En sus libros posteriores, Berenguer se acerca nás a una escritura neovanguardista, donde el referente está obliterado.

8 En Berenguer, no hay procedimientos diferentes entre la casa y la calle, por ello en el tálamo se repiten las jerarquías públicas del género: "Cópulas Cúpulas / Cúpulas Cópulas /Y yo siempre debajo" (65). La administración del cuerpo en la intimidad amorosa es un hecho político donde se ejercen las tácticas de subordinación del Estado autoritario, es decir, la máquina de la jerarquía se utiliza en todos los espacios, es in-ubicua.

9 El tema de la casa ha continuado en la producción de Berenguer. Tatiana Calderón lo estudia en Naciste pintada, la crítica dice: "El espacio de la casa consta de varias asociaciones significantes: útero (primer mundo), sepulcro, ideologema, territorio patriarcal, subcultura femenina, lugar de trabajo invisible, sexualidad femenina" (49). Dentro de las casas trabajadas por Berenguer, sobresale el prostíbulo, comprendido como casa pública.

10 El libro El barro lírico de los mundos interiores más oscuros que la luz (2003) de Héctor Hernández no posee números de páginas, otra ironía más para el lector ilustrado. 
exaltación por medio del maquillaje y del vestuario de las características femeninas ${ }^{11}$. Sobre el vínculo entre vestuario y prostituta, Michelle Perrot indica: "las cortesanas, seducen a las mujeres antes que a los hombres, por ejemplo en la moda" (33). Santiago, tal como una prostituta, se ha puesto un traje que lo vuelve visible, un escenario que se viste con falsas pieles para simular modernidad. El traje inauténtico está dado por la liberalización de las políticas del suelo, que obligó a los grupos populares a desplazarse hacia las zonas suburbanas, lo que generó la división entre el Santiago 'patipelado' y el Santiago acomodado. Berenguer problematiza el auge de la construcción en algunas comunas, debido a la ley de 1979 que establecía el "Programa de viviendas básicas o Programa de erradicación de campamentos". Esta ley significaba sacar de ciertas comunas las poblaciones pobres para llevarlas al extraradio de la ciudad, lo que generó "una mayor homogeneidad social en las comunas. Por ejemplo, las de Providencia y Las Condes reafirmaron su carácter de comunas habitadas por familias de clase alta, mientras que La Granja, La Pintana, San Ramón y otras del sector sur occidental pasaron a ser comunas de clase baja y media baja" (De Ramón 255). El fin de los planes urbanísticos trajo la consecuente proliferación de andamios en la ciudad que Berenguer representa en "Andamiaje". Me llama la atención que en este poema ella describe el auge de la construcción como"dulce azúcar del relajo" (Berenguer 29), vale decir el nuevo sistema produciría satisfacción tanto para el obrero, llamado "sibarita maestro", como para el empresario. El obrero ya no es retratado con "los dedos machacados" (Neruda 36), Berenguer se da cuenta de que el neoliberalismo marca el fin de una concepción del obrero. El crecimiento vertical de la ciudad, es visto como una modernidad de decorado y fachada, pero sin fuerza industrial, a pesar de lo cual causa agrado a ciertos sectores populares. Como en un burdel, la ciudad neoliberal escondió la pobreza y exhibió sólo sus ricos ropajes.

La siguiente denominación para la metropolí chilena es 'patipelá' (Berenguer 17), calificativo que remite al sujeto que no tiene zapatos, que no es dueño de territorio, que vaga y hace ostensibles sus pies desnudos, metonimia de la erradicación. Recordemos que Mistral en Poema de Chile se refiere a la cuestión de la tierra y usa una demoninación muy similar: "Te voy llevando a un lugar/ donde al mirarte la cara/ no te digan como nombre / lo de indio pata rajada" (Mistral p....). Berenguer vuelve a la figura del habitante como un patipelado, lo que explica, me parece el título Huellas de siglo, en razón de que es un problema transhistórico. Si antes la erradicación la realizó el español, ahora la hace la dictadura que transforma la ciudad en un espacio bélico y reglamentado similar

11 En relación con la femenidad, Severo Sarduy afirma que "el travesti no imita a la mujer. Para él, (no) hay mujer, sabe - y quizás, paradójicamene sea el único en saberlo-, que ella es una apariencia, que su reino y la fuerza de su fetiche, encubren un defecto" (55) 
a la Colonia. De ahí que la hablante retome el calificativo de 'ciudadela' (35), con lo cual Santiago es connotado como territorio encerrado, recinto de fortificación permanente y ciudad militarizada. El tema de la expulsión aparece también en El paseo Ahumada (1983) de Enrique Lihn quien dice:"tan cesantes como estábamos los araucanos en el decir de los conquistadores" (Lihn 69). El poemario de Berenguer presentaría dos subjetividades populaes: los prostituidos o consumidores y los expulsados, patipelados o cesantes. Tal como el Santiago colonial se configuraba en relación con una potencia extranjera, el Santiago dictatorial es visto como una urbe dominada por los mercados trasnacionales que imponen la guerra del capitalismo: 'war, war' (11) o 'Der Krieg, Der Krieg' (11). La nueva ciudad es 'patipelá' en el sentido que no ofrece al individuo un territorio al cual integrarse en propiedad, sino que le proporciona un espacio de uso momentáneo e inestable. La ciudad entonces no es propiedad de sus habitantes ${ }^{12}$ no consumidores, pero tampoco sigue el modelo del prostíbulo chileno cuyo dueño es la oligarquía. Los nuevos dueños son quienes se desempeñan como "cafiche" (Berenguer 17) del modelo, lease las fortunas de familias sin apellido iniciadas en la dictadura. El burdel es sólo un espacio de acogida transitorio para las patipeladas pobres que han sido también expulsadas del consumo.

La sujeto de los poemas se define también como prostituta, en razón de los modos identitarios que ocupa en la ciudad y que corresponden a un 'guión hecho y acartonado'13 diría Lucía Guerra. Esta identidad hecha corresponde al modelo de la Marianne que asume la sujeto con una cierta distancia, pues comprende que hay allí una representación masculina de las mujeres en la lucha por la libertad. No olvidemos que el famoso cuadro La libertad guiando al pueblo sobre las barricadas (1830) de Eugène Delacroix es una representación efectuada por un hombre. En el poema "Matadero Palma", ella viaja en una micro de ese recorrido, comportándose de forma vivaz: saca una bandera por la ventana, canta y es rociada de flores por un pelusa. El comportamiento según un heteromodelo la lleva a autocalificarse de "ramera" (38). Tal condición tiene que ver con asumirse en función de agradar a un hombre; por ejemplo,

Hay un momento en que la voz se revela contra esa ciudad que no es de su propiedad y ve como única solución, el incendiarla.

13 Lucía Guerra examina que la ciudad propone diversas maneras de ejercer el género y por ello, "La ciudad es uno de los factores cruciales en la producción social de la corporalidad sexual puesto que la edificación y distribución del espacio urbano provee el contexto y coordina las formas contemporáneas del cuerpo. Orden y organización que reafirman una agrupación en categorías genéricas que ligan o distancian esos cuerpos, que los legitiman o reducen a lo ilegítimo en diversos procesos de territorialización. La ciudad es así una condición y un medio más a través del cual se produce la corporalidad a nivel social, sexual y discursivo" (289) 
en el poema "Metro"14, hace un recorrido subjetivo de esos lugares y de la estación "Santa Lucía" recuerda sus amores en el cerro: "Te amo más que a mi pelo/ más que a mis ojos/ más que a mi cuerpo/ porque ya es tuyo" (20). Aquí está el ser para otro, como la figura de la prostituta. La ciudad ramera es sostenida por la mujer que funciona como prostituta, que se viste también con falsas pieles y cuya función es ser acompañante de un varón: " De dónde esta locura/ de acompañarte por las noches / con este negro y este rojo / esta bufanda que es una bufonada / y esta vitrina que devuelve esta pirueta / esta artesanal pinta hecha a la medida" (Berenguer 23). Los colores negro y rojo del Movimiento de izquierda revolucionario (MIR) son reducidos al registro de la moda como en la mujer prostituta. La mujer acompañante se retrata a sí misma como un cuerpo para otro: "Mi carne para su goce / mi orgullo para su látigo/ mi protesta para su cárcel / mi infierno para su edén / mis amuletos para su suerte/mi locura para sus sueños / mi muerte para su vida" (57). En este poema titulado "Vampiro" "la experiencia erótica se analogiza a la de la tiranía" (Brito 168), donde ella asume, con distancia, que su cuerpo está para el goce, para ser golpeado, para ser hecho prisionero y también, paradojalmente, para soñar. La voz tiene conciencia de que la mujer en función de acompañante ocupa el rol de una prostituta, pero este darse cuenta no le genera la fuerza para emanciparse.

Otra forma de desplazamientos por la ciudad es la mujer en el rol ama de casa y de madre. La división de fronteras casa/ calle ya había sido traspasada en Chile antes del golpe de 1973, cuando las mujeres desbordaron el espacio doméstico, ya sea descontextualizando el rol de ama de casa, llevándolo a la calle con los 'cacerolazos'15 ; o, luego, bajo el rol de madre, mediante las protestas a favor de sus hijos(as) torturados y/o detenidos desaparecidos (Pizarro 201). La ama de casa vuelve a Santiago "pobre dama" , en tanto, la noción de 'dama' remite al amor cortés, donde "la regla es que un joven, un caballero célibe, escogiera a una dama, la esposa de un señor, para servirla, remedando las actitudes de los vasallos" (Casenave 58). Entonces, Santiago como pobre dama es la exigencia realizada por las mujeres cuando han salido a la calle para pedir a a otros su salvación. El otro desplazamiento es ejercido por la madre que busca de alimento: "Duerme la ciudad - Santiago duerme y tiembla/ (...) Compraré al alba un pan"(Berenguer 33). Esta figura de la madre peregrina se asigna la tarea de oponerse a los lugares de punición,

14 El Metro p uede ser considerado un referente ligado a la dictadura, pues fue inaugurado el 15 de septiembre de 1975, con un tramo que iba desde San Pablo hasta la Moneda. Luego en 1977 se extendió hasta Salvador y en 1980 hasta Escuela Militar. La línea 2 se abrió en marzo de 1978, inicialmente iba desde Los héroes hasta Franklin y luego, ese mismo año, hasta Lo Ovalle.

15 El 'cacerolazo' o golpeteo de la olla producido desde el patio o la ventana de la casa permitía el anonimato de la opositora. 
prisión y tortura que 'reducen' al detenido, le anulan su condición de adulto, y emplazan a la mujer a su papel de madre en búsqueda de su hijo. El recurso de infantilizar tiene un antecedente poderoso en Chile donde, siguiendo a Sonia Montecino, los huachos están siempre en la condición de hijos, son los pequeños para sus madres, los hijos para el ejército o un ahijado para el padrino laboral. Algunos de los versos del poema 'Homenaje' aluden a esta condición de hijos en que se sitúan hombres adultos "y no me encuentras más en aquel rincón / chupándome el pulgar." (45). Si bien el epígrafe dedica el texto "a Juan Aguirre Ballesteros"16 ${ }^{\prime 16}$ detenido desaparecido, el drama se hace extensible a la comunidad. El posicionamiento en el rol de madre consolida una estrategia mariana ante el conflicto y es el único lugar desde el cual la mujer puede recorrer plenamente la ciudad.

\section{Conclusiones}

Mis inquietudes se refieren al grado de transgresión con se efectúa ese escribir la ciudad desde un lugar femenino. Lo que hace Berenguer en Huellas de siglo es tratar la ciudad como si fuera una mujer. La ciudad neoliberal estaría hecha para ser vendida, adornada con productos suntuarios, creando así el agrado de los sectores populares con trabajo y entonces, acceso al consumo. Berenguer expresa su molestia ante esta ciudad del intercambio llamándola ciudad prostituta. Sin duda, es una imagen que nos hace reflexionar sobre la relación entre mercado, mujer y ciudad, mediante la exageración de las similitudes entre ciudad neoliberal y burdel. La prostituta ya no es un tipo particular de ciudadanía, como analizaba Benjamin en Baudelaire, sino la forma común de habitar esta urbe: la izquierda, la derecha, las etnias y algunas formas de credo se vuelven mercancía para el mercado. Sin embargo, emplear la figura de la prostituta para señalar esto, corre el riesgo de volver a insistir en la demonización de la mujer. Lo positivo es que la exageración de ese rol, nos permite ver la facilidad con que lo ejercemos el estar disponibles como cuerpos en vitrina.

Efectivamente en el poemario se satisface esa devaluación de la hablante que K Oyarzún había señalado como tendencia en la escritura de mujeres del periodo. Esta devaluación sólo puede tener como objetivo el tomar conciencia de las matrices identitarias en que nos movemos: cuerpo sometidos, bien transable, o los roles clásicos de marianne o madre. El riesgo es que el poemario no alcanza a proponer identidades

16 Juan Aguirre Ballesteros, panadero, fue detenido en 1984, después de 51 días apareció su cadáver en un canal de regadío de Codegua. 
nuevas más allá de mujer, mercancia, prostituta, lo que se comprende, dado que está inscrito en un momento de crítica a los roles clásicos del ejercicio del género. Dentro de este gesto que está entre repetir el modelo aprendido y tomar distancia de él, ubico la performance de Eltit en el burdel que contempla el situarse como otra prostituta más que cumple una función cotidiana, lavar la acera; pero también puedo ver el riesgo, hay un uso de los mismos significantes del discurso dictatorial, como en este caso, la limpieza. La devaluación no es de la prostituta, sino de su metáfora, la ciudadanía ideal como prostituta. Otra lectura, complementaria, es ver esta asociación de las escritoras con el burdel, como una imagen de la función de la artista en el capitalismo, situación ya apreciada por Benjamín que aquí alcanzaría un grado de obscenidad, puesto que el artista se traslada al lugar de las ventas.

El poemario de Berenguer trabaja sobre un sistema: el proyecto político ha modificado la ciudad, ha puesto fin al espacio planificado desde el Estado, ha introducido el flujo de los objetos y de los cuerpos, es decir ha reorganizado los espacios y por tanto, nos obliga a repensar cómo van a ser distribuidos los roles de género en estos nuevos intercambios. Su pregunta sigue susurrando: ¿repetiremos las huellas de los siglos?.

\section{Bibliografía}

Benjamin, Walter.

Poesía y capitalismo: Iluminaciones II. Trad. Jesús Aguirre. Madrid: Taurus, 1988.

Brito, Eugenia.

"La oralidad como proceso de producción de la escritura". Campos minados. Santiago: Cuarto propio, 1994: 165-172.

Berenguer, Carmen. Huellas de siglo. Santiago: Ediciones maniaristas, 1986.

Cánovas, Rodrigo. Sexualidad y cultura en la novela hispanoamericana: La alegoría del prostíbulo. Santiago: Lom, 2003.

Calderón, Tatiana. $\quad$ "Cartografía de la ciudad: La casa subversiva en Naciste pintada (1999) de Carmen Berenguer". Alpha 22. Universidad de los Lagos, julio, 2006: 43-55.

Cárcamo-Huechante, Luis Ernesto.

"Hacia una trama localizada del mercado: Crónica urbana y economía barrial en Pedro Lemebel". Más allá de la ciudad letrada: Crónicas y espacios 
Cazenave, Michel.

Comblin, José.

De Ramón.

Guerra, Lucía.

Hernández, Héctor.

Lihn, Enrique.

Moi,Toril.

Montecino, Sonia.

Mistral, Gabriela.

Neruda, Pablo.

Neustadt, Robert.

Olea, Raquel.

Perrot, Michelle.

Pinochet, Augusto.

Pizarro, Ana. urbanos. Muñoz, Boris y Silvia Spitta (ed). Universidad de Pittsburgh, 2003. Pp.69- 137

"El amor imposible". El arte de amar en la Edad Media . Editores Michel Cazenave, Daniel Poiron et al. Barcelona: Medievalia, 2000: 51-90.

El neoliberalismo: Ideología dominante en el cambio de siglo. Santiago: Cesoc - Lom, 2001.

Santiago de Chile. Santiago: Sudamericana, 2000.

“Género y cartografías significantes en los imaginarios urbanos de la novela latinoamericana". Más allá de la ciudad letrada. Comp. Boris Múñoz y Silvia Spitta. Universidad de Pittsburgh, 2003: 287-306.

El barro lírico de los mundos interiores más oscuros que la luz. Santiago: Contrabando del bando en contra, 2003.

El Paseo Ahumada. Santiago: Ediciones Universidad Diego Portales, 2003.

Teoría literaria feminista. Trad. Amaia Bárcena. Madrid: Cátedra, 1988.

Madres y huachos: Alegorías del mestizaje chileno. Santiago: Sudamericana, 2001.

"¿A dónde es que tú me llevas". Poema de Chile. Santiago: Seix Barral, 1985: 139-140.

Canto general. Bogotá: Oveja negra, 1986.

CADA/Colectivo de acciones de arte. Santiago: Cuarto propio, 2001

"La señal de las hablas: La poesía de Carmen Berenguer". Lengua víbora: Producciones de lo femenino en la escritura de mujeres chilenas. Santiago: Cuarto propio, 1998: 131-146.

Mujeres en la ciudad. Trad. Oscar Molina. Santiago: Andrés Bello, 1997.

Patria y democracia. Santiago: Editorial Andrés Bello- Corporación de estudios nacionales, 1983.

"La casa y la calle: Mujer y cultura en América Latina y el Caribe". De ostras y caníbales. Santiago: Edcs de la Universidad de Santiago, 1994:193-207 
Real Academia Española (RAE).

Diccionario de la Lengua Española. Madrid: Espasa Calpe, 1992.

Sarduy, Severo.

"La simulación". Ensayos generales sobre el barroco. Buenos Aires: Sudamericana, 1974.53-111. 